\title{
Thermostabilizing annealing analysis of organomorphic preforms made of oxidized polyacrylonitrile
}

\author{
Pavel Prosuntsov ${ }^{1, *}$, Evgeniy Bogachev ${ }^{2}$, and Alexander Elakov ${ }^{2}$ \\ ${ }^{1}$ Bauman Moscow State Technical University, Department of Rocket and Space Composite \\ Structures, 105005 Moscow 2-nd Baumanskaya 5, Russia \\ 2 JSC "Kompozit", Nonmetallic materials direction, 141070 Korolev city Pionerskay 4, Russia
}

\begin{abstract}
The simulation results of the thermal stabilization of polyacrylonitrile pressed organomorphic frame samples are presented. The local temperature maximum in the sample depth due to an exothermic oxidation reaction was confirmed. The possibility of the avalanche exothermic effect, which can lead to a sample burnout, is demonstrated theoretically. The analysis of the influence of the initial fiber oxidation degree on the sample temperature state have been carried out.
\end{abstract}

\section{Introduction}

The methods for obtaining reinforced frames made of composite materials are characterized by a large variety of technologies and equipment [1]. Nowadays researchers' attention is drawn to organomorphic frames that consist of carbonized pressed polyacrylonitrile (PAN) [2-6]. In the manufacturing of reinforced carbon-carbon (RCC) and ceramic matrix composites (CMC) as a feedstock both PAN tows or nonwoven pressed samples are used. The first stage of the RCC and CMC manufacturing is to conduct thermal stabilization (oxidation) of the initial PAN feedstock. During the thermal stabilization process, cyclization and oxidation of the PAN preform occur. It is significant fact from the manufacturing point of view that the thermal stabilization process proceeds with a definite exothermic effect, therefore, too rapid heating of the PAN preform can lead to the excessive heat generation and thermal burnout of the preform. In the manufacturing of the continuous carbon filaments [5-6], this heat is removed by fibers blow-off with a large volume of air that allows to achieve the temperature difference in the fiber along the length of no more than 2 degrees that is impossible during heat treatment of pressed preforms.

The object of the study is organomorphic frame made of non-woven fabric Oxypan ${ }^{\circledR}$ $[7,8]$, consisting of partially oxidized PAN staple fibers Pyron ${ }^{\circledR}$. Plates of the required thickness were assembled from fabric pieces by fastening with a needle-punched method and subsequent pressing under force from $5 \mathrm{MN}$ to $50 \mathrm{MN}$.

The purpose of the study is to research influence of exothermic effect that occurs during thermal stabilization of the organomorphic frame on the sample temperature state.

\footnotetext{
* Corresponding author: pavel.prosuntsov@mail.ru
} 


\section{Thermal stabilization model}

The thermal stabilization process of the preform made from pressed organomorphic frame in electric furnace was simulated (Fig.1). Heaters made of nichrome wire were wound on ceramic tubes were heating source. A steel box with a sample was mounted on ceramic and steel plates placed on the furnace hearth. A sample of the organomorphic frame in the form of a pressed PAN plate with dimensions of $95 \times 95 \times 40 \mathrm{~mm}$ was clamped between two steel plates. To create pressure a massive steel load was placed on the sample upper surface. The uniformity of sample heating was increased by filling the box with furnace coke to a height of approximately two-thirds of the overall size. The rest of the box remained free.

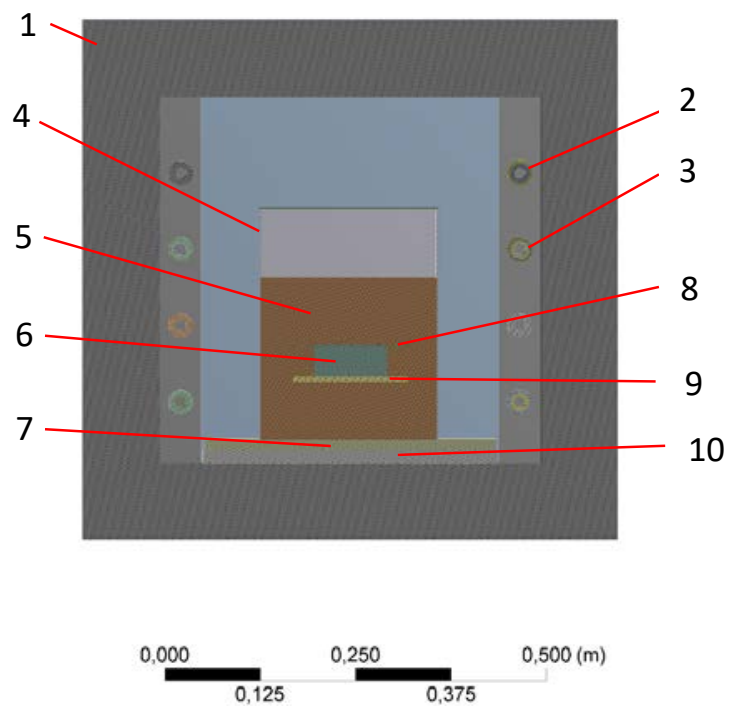

Fig. 1. Geometrical model of the thermal stabilization furnace with organomorphic frame sample box mounted in it (steel load not shown for clarity) 1- furnace insulation; 2 - nichrome heaters; 3 -

alundum tubes; 4 - steel box; 5 - furnace coke filling; 6 - sample of the organomorphic frame; 7-9 steel plates; 10 - ceramic plate

Physical and mathematical models of heat transfer in the thermal stabilization furnace were developed. A three-dimensional steady-state process of combined radiationconductive heat transfer was considered. In the simulation, the experimentally measured dependence of the nichrome heaters power on time was used. Herewith it was assumed that the heaters power was uniformly generated over their entire volume. The radiation heat transfer was considered separately for two areas - in the main furnace volume and in box cavity free from filling. In both cases radiating and reflecting surfaces were assumed as gray and diffuse. The gas medium in the furnace volume was taken diathermic radiationtransparent. Convective heat transfer was not taken into account. Conductive heat transfer in all solid bodies was also simulated in furnace insulation, ceramic tubes and plate, box frame, filling and load. Materials' thermophysical properties were temperature dependent. It was taken into account that during thermostabilizing annealing physicochemical transformations in the organomorphic frame sample occured with the heat generation. Also the extent of thermal stabilization reaction, i.e. physicochemical transformations in the sample, was determined by Arrhenius equation.

The values of the activation energy, pre-exponential factors and heat of thermal stabilization reaction at this stage were taken from other researches where the thermal stabilization of the continuous PAN fiber was previously experimentally studied $[9,10]$. 
However, in this case, in contrast to [9, 10], a preliminary partially oxidized PAN fiber was used, i.e. the process of physicochemical transformations in the fiber had already partially completed. Unfortunately, the material manufacturer did not provide data on the value of the oxidation degree Oxypan ${ }^{\circledR}$. Therefore, a parametric study of the effect of the initial fiber oxidation degree on the sample temperature state was carried out.

\section{Influence analysis of exothermic effect on the sample temperature state}

The simulation results showed (Fig. 2) that the temperature field and the oxidation degree field of thermal stabilization reaction were high heterogeneous. A significant temperature difference in the $\mathrm{X}$ direction could be explained by the sample shift relative to the transverse symmetry plane of the furnace.

Fig. 3 and 4 depict the temperature and oxidation degree changes during thermal stabilization. It is apparent (Fig.3) that the temperature in the sample center in intense physicochemical transformations area was higher than on the external surface. Due to this (Fig.4) the rate of physicochemical transformations in the sample center was significantly higher, i.e. in the sample center the transformation process began later and completed earlier than on the external surfaces.

The maximum values of the volumetric heat generation, which characterizes the exothermic effect of physicochemical transformations that is directly related to the oxidation degree rate, also were significantly higher exactly in the sample central area (Fig. 5). The analysis showed that this effect is explained by the obstructed heat removing from the central area that was associated with a low thermal conductivity coefficient of the organomorphic frame (approximately $0.06 \mathrm{~W} /(\mathrm{m} \cdot \mathrm{K})$ ).

The simulation results suggest that during about $160000 \mathrm{~s}$ the thermal stabilization in a pressed Oxypan ${ }^{\circledR}$ sample was fully completed, while the oxidation started from 40,000 s from the beginning of the thermal stabilization and basically finished after 100,000 s. The maximum exothermic effect of thermal stabilization was about 60,000 s from the process beginning.

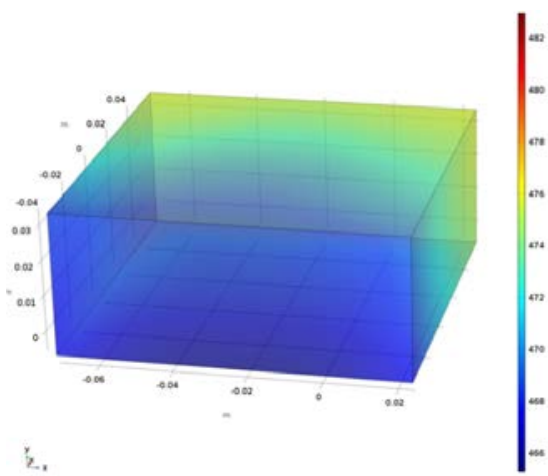

a)

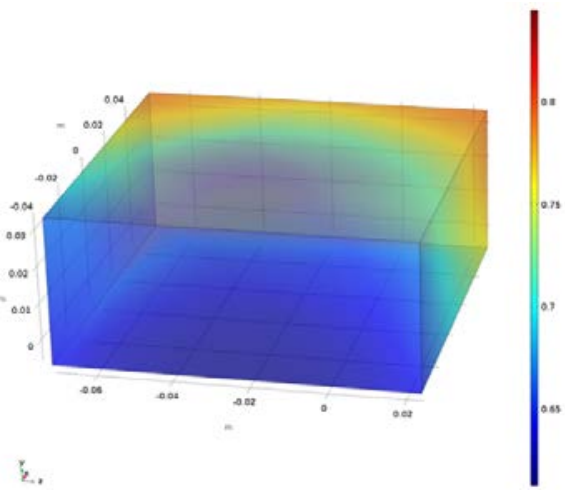

b)

Fig. 2. The temperature field (a, K) and oxidation degree (b) of the organomorphic frame sample at the time point of $59700 \mathrm{~s}$ at the initial value of the oxidation degree 0.5 


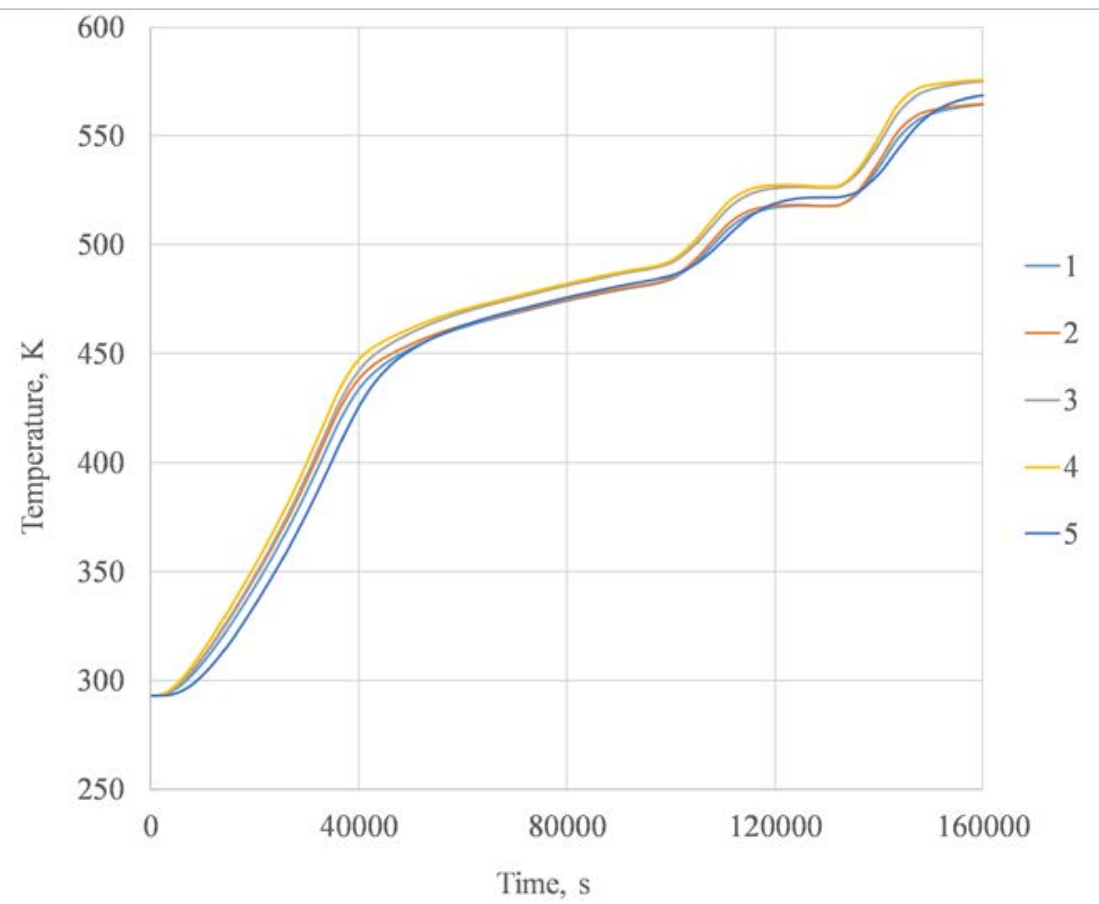

Fig. 3. Temperature change in the nodal points (1-4) and center (5) of the sample

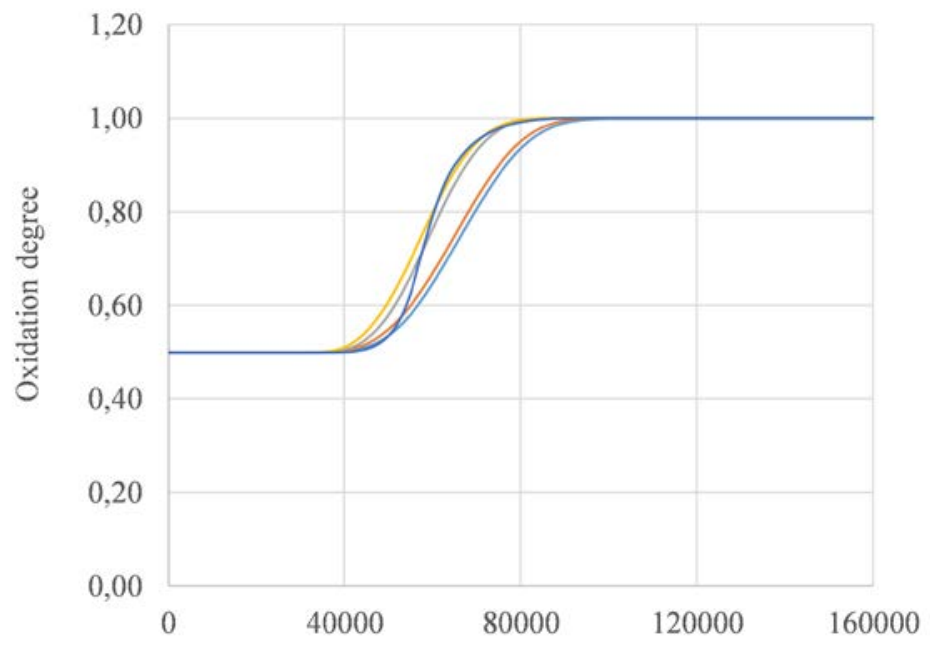

Time, $\mathrm{s}$

$-1-2-3-4-5$

Fig. 4. Oxidation degree change in the nodal points (1-4) and center (5) of the sample 


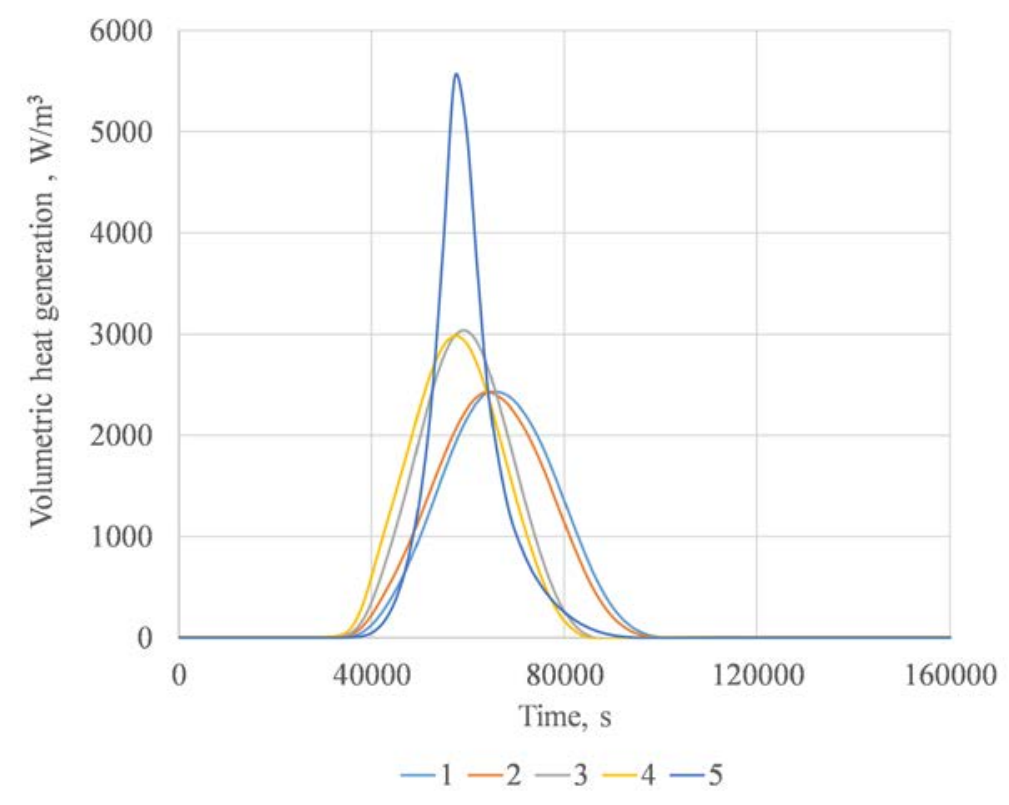

Fig. 5. Volumetric heat generation change in the nodal points (1-4) and center (5) of the sample

\section{Influence analysis of initial oxidation degree on sample temperature state}

The study of the influence of initial oxidation degree of the organomorphic frame showed that the exothermic effect occurred in the sample central area significantly affects on the dynamics of its temperature state (Fig. 6). It is apparent that the temperature rise in the sample center above the peripheral areas increased sharply with a decrease in the initial oxidation degree. Also, at a value of 0.25 , an avalanche exothermic effect began. Note, in manufacturing it could lead to organomorphic frame burnout. Fig. 7 depicts the temperature history in the sample center at different initial values of the oxidation degree compared to the no-exothermic effect case. At the same time, the initial value of the oxidation degree had practically no influence on the physicochemical transformations dynamics, i.e. the time of the process beginning and completion practically coincided (Fig. 8).

The time moment of the occurrence of volumetric heat generation peak value was slightly shifted to the smaller values area. But the maximum heat generation values were significantly changed (Fig. 9).

The simulation results made it possible to correct the thermal stabilization temperaturetime regime, minimize the negative influence of the exothermic effect in the volume of pressed material and avoid the fibers burnout during the pyrolysis of compacted polymer fibers.

To assess the exothermic effect influence in the volume of the organomorphic frame, an experimental temperature measurement was performed at various sample points. The hot junction of one thermocouple was placed in the sample central part in a previously prepared recess. The second junction was located on the sample edge. The comparison of the experimental and calculated values of temperature showed that the developed model of thermally stabilized annealing adequately illustrates the basic principles of the thermal stabilization (Fig. 10). 


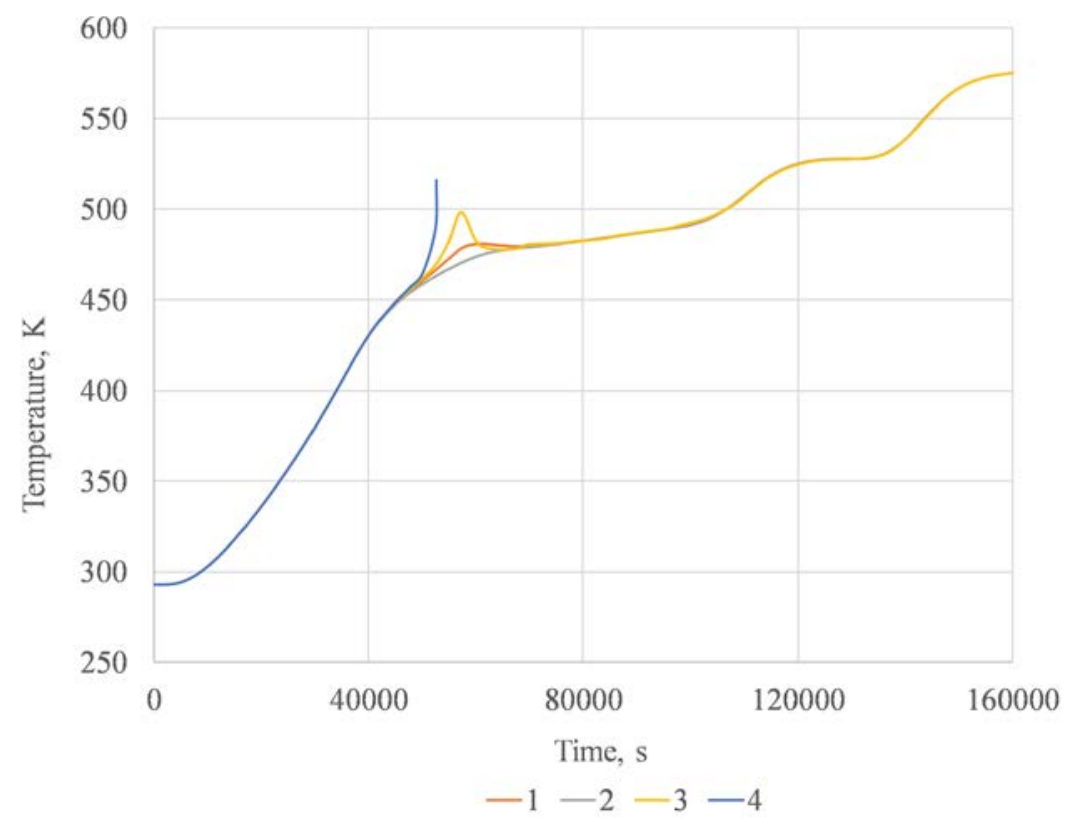

Fig. 6. The temperature change in the sample center of the organomorphic frame at different initial values of the oxidation degree $1-0.25 ; 2-0.40 ; 3-0.50 ; 4-0.70$

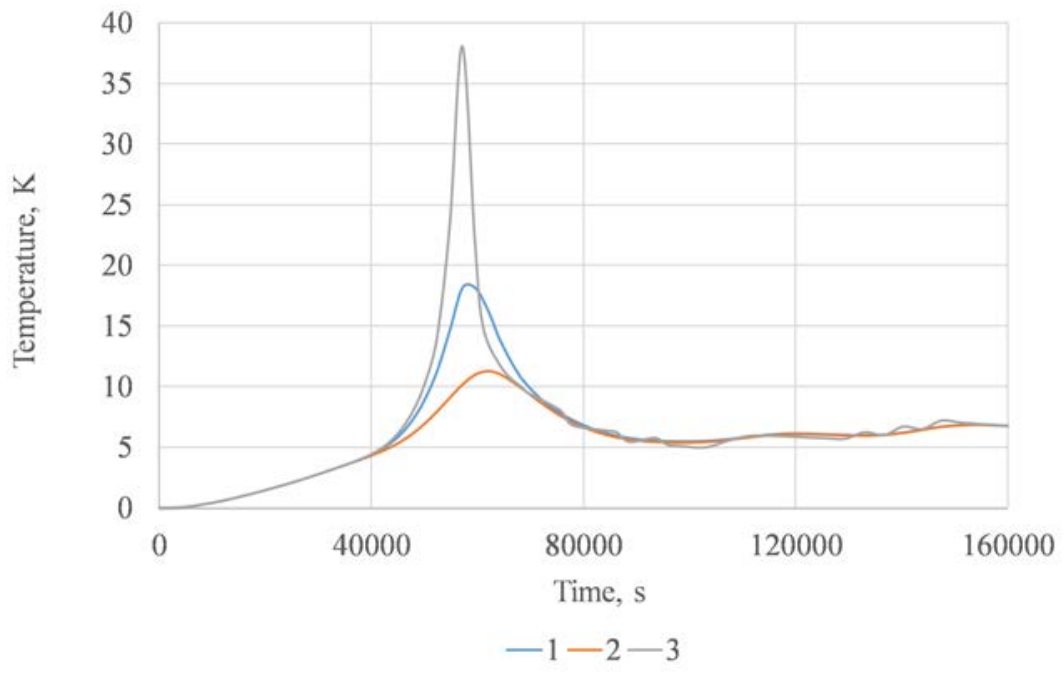

Fig. 7. The temperature rise in the sample center along the organomorphic frame at different initial values of the oxidation degree $1-0.4 ; 2-0.5 ; 3-0.7$ 


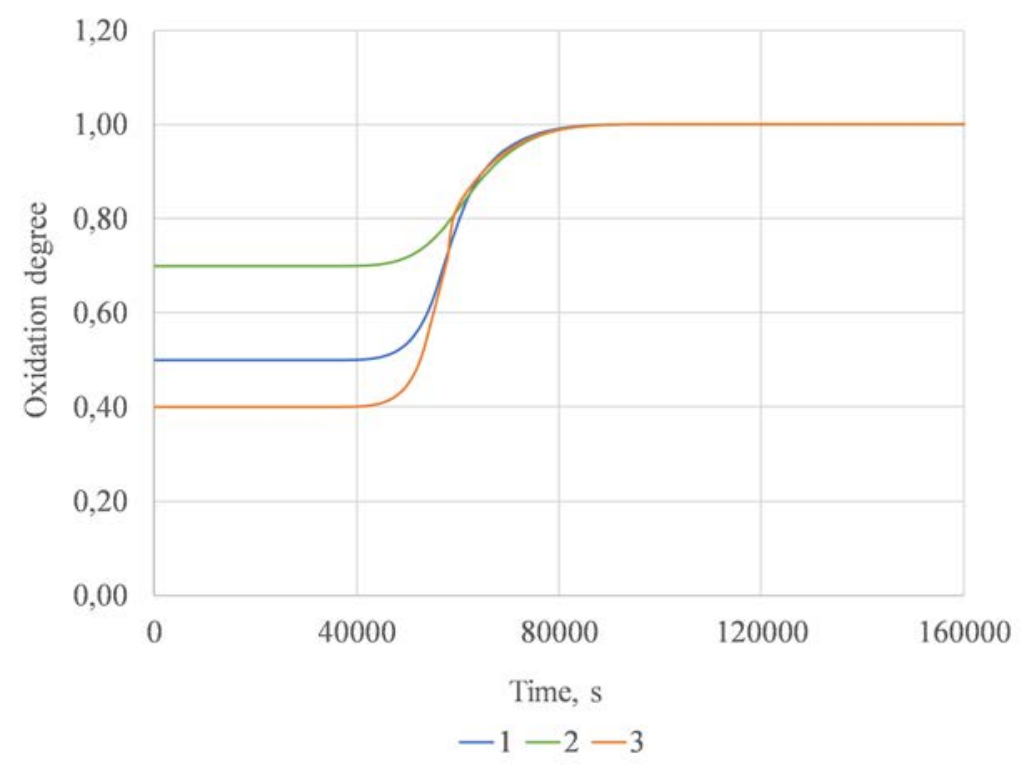

Fig. 8. The change in the oxidation degree in the sample center of the organomorphic frame with its various initial values $1-0.4 ; 2-0.5 ; 3-0.7$

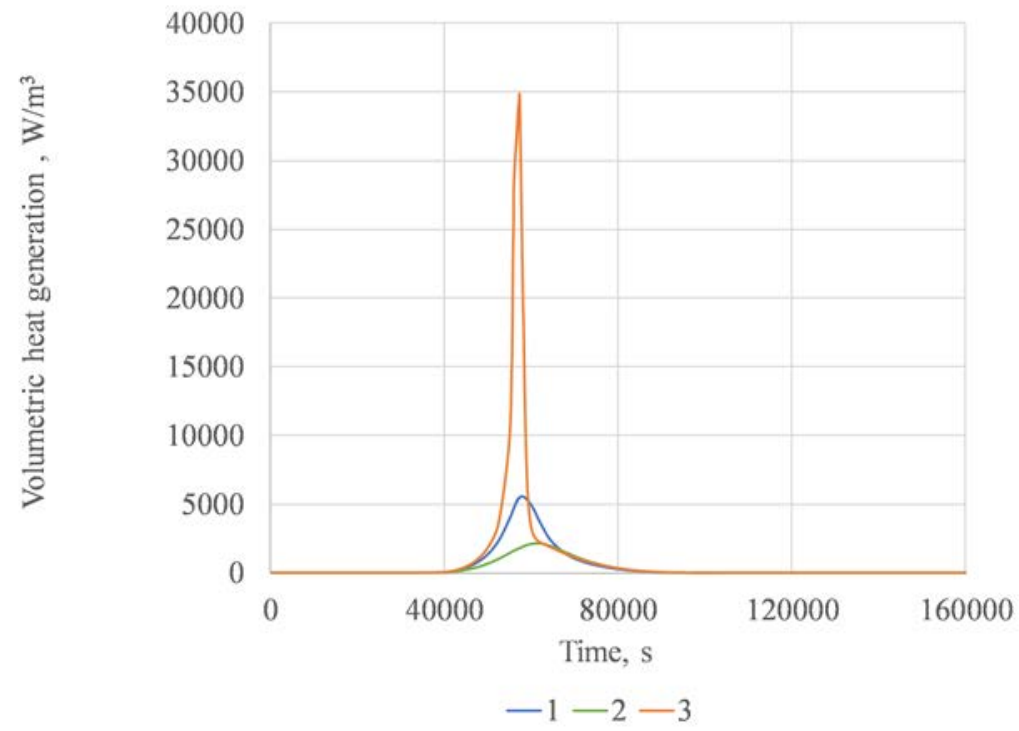

Fig. 9. The change in volumetric heat generation in the sample center of the organomorphic frame at different initial values of the oxidation degree $1-0.4 ; 2-0.5 ; 3-0.7$ 


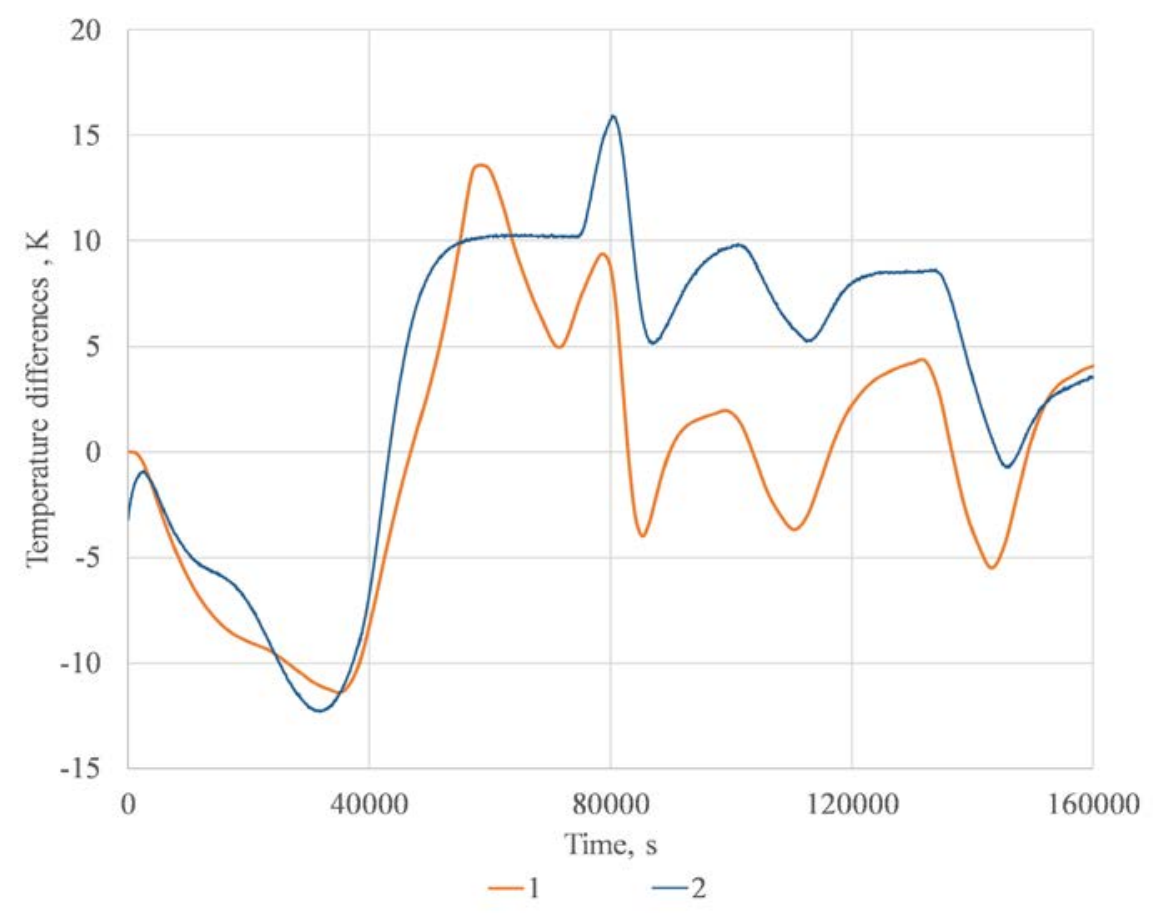

Fig. 10. Calculated (1) and experimentally measured (2) temperature differences between the sample center and the edge in the thermal stabilization process

\section{Conclusions}

The simulation results indicate the following basic principles of the thermal stabilization process:

- the negative value of the temperature difference between the sample center and its edge before the occurrence of the thermal stabilization exothermic effect;

- a significant (up to 10-15 K) temperature excess in the sample center over the temperature of its edge during the intensive thermal stabilization reaction;

- reduction of temperature difference at the moment of heaters power increase;

- a significant dependence of the exothermic effect intensity on the initial oxidation state of the frame material;

- the possibility of an avalanche exothermic effect that could lead to the sample burnout.

\section{References}

1. I. Bulanov, V. Vorobey Tekhnologiya raketnykh i aerokos-micheskikh konstruktsiy iz kompozitsionnykh materialov (Publishing house BMSTU, Moscow, 1998)

2. S. Reznik, P. Prosuntsov, K. Mikhailovskii, Journal of Engineering Physics and Thermophysics, 88, pp. 594-601 (2015).

3. P. Prosuntsov, N. Taraskin, Matec Web of Conferences, 72, 01092 (2016).

4. S. Reznik, K. Mikhailovskii, P. Prosuntsov, Journal of Engineering Physics and Thermophysics, 90, pp. 291-300 (2017).

5. P. Prosuntsov, N. Taraskin, Matec Web of Conferences, 92, 01008 (2016). 
6. S. Reznik, P. Prosuntsov, K. Mikhaylovskiy, Matec Web of Conferences, 224, 03019 (2018).

7. E. Bogachev, A. Elakov, A. Beloglazov, Yu. Denisov, A. Timofeev, Method of manufacturing porous base scaffold of composite material, Russia Patent, 2017.

8. E. Bogachev, Composites and nanostructures, 9, pp. 12-23 (2017).

9. V. Birukov, Optimizaciya processa termostabilizacii pri poluchenii uglerodnogo volokna na osnove poliakrilonitrila, The thesis for the degree of Doctor of Technical Sciences (2002).

10. A. Isaev, Sovershenstvovanie teplovoj raboty pechi termostabilizacii pri proizvodstve uglerodnyh volokon s cel'yu snizheniya energozatrat, The thesis for the degree of Doctor of Technical Sciences (2016). 